ORIGINAL ARTICLE

\title{
Atrazine in municipal drinking water and risk of low birth weight, preterm delivery, and small-for-gestational-age status
}

\author{
C M Villanueva, G Durand, M-B Coutté, C Chevrier, S Cordier
}

Occup Environ Med 2005;62:400-405. doi: 10.1136/oem.2004.016469

See end of article for authors' affiliations

Correspondence to: Dr C M Villanueva, Respiratory and

Environmental Health Research Unit, Institut Municipal d'Investigació Mèdica (IMIM), C/Doctor Aiguader, 80, 08003Barcelona, Spain; cvillanueva@imim.es

Accepted 1 February 2005

\begin{abstract}
Background: Atrazine is a herbicide used extensively worldwide. Bioassays have shown that it is embryotoxic and embryolethal. Evidence of adverse reproductive outcomes from exposure in the general population is sparse.

Aims: To evaluate the association between atrazine levels in municipal drinking water and the following adverse reproductive outcomes: increased risk of preterm delivery, low birth weight (LBW), and small-forgestational-age (SGA) status.

Methods: A total of 3510 births that took place from 1 October 1997, to 30 September 1998 were analysed. Atrazine measurements were available for 2661 samples from water treatment plants over the past decade. A seasonal pattern was identified, with atrazine peaking from May to September. The geometric mean of the atrazine level for this period was calculated for each water distribution unit and merged with the individual data by municipality of residence.

Results: Atrazine levels in water were not associated with an increased risk of LBW or SGA status and were slightly associated with prematurity. There was an increased risk of SGA status in cases in which the third trimester overlapped in whole or in part with the May-September period, compared with those in which the third trimester occurred totally from October to April $(O R=1.37,95 \% \mathrm{Cl} 1.04$ to 1.81$)$. If the entire third trimester took place from May to September, the OR was 1.54 (95\% Cl 1.11 to 2.13).

Conclusions: Low levels of atrazine, a narrow exposure range, and limitations in the exposure assessment partly explain the lack of associations with atrazine. Findings point to the third trimester of pregnancy as the potential vulnerable period for an increased risk of SGA birth. Exposures other than atrazine and also seasonal factors may explain the increased risk.
\end{abstract}

A trazine is a herbicide from the triazine group used for weed control in a variety of crops, especially maize. Since its introduction in 1957, atrazine has been one of the herbicides used most extensively worldwide. Exposure is expected to be high in occupational settings (for example, application by agricultural workers), through dermal contact or inhalation. Levels reported in the personal breathing zone range from 0.24 to $0.89 \mu \mathrm{g} / \mathrm{l}^{1}$ Atrazine does not tend to bioaccumulate, but its relative persistence (half-life of 35125 days in the environment, depending on conditions) and mobility in some types of soil can contaminate surface and ground waters. Atrazine is found in rivers, lakes, ground waters, reservoirs, and rainwater as a result of its extensive use in agriculture..$^{2-5}$ Consequently, the general population could be exposed to atrazine through ingestion of contaminated drinking water, as well as consumption of contaminated food or aerial drifts from spraying. In 1998, a European Union (EU) directive set the maximum concentration of atrazine and other pesticides in drinking water at $0.1 \mu \mathrm{g} / \mathrm{l} .{ }^{6} \mathrm{~A}$ number of EU countries, including France, Italy, Austria, Denmark, Germany, Norway, and Sweden, have recently banned use of this herbicide, which is still widely used in the United States and elsewhere. The frequency with which it was detected at levels exceeding $0.1 \mu \mathrm{g} / \mathrm{l}$ in drinking water was one of the principal reasons for its ban in many EU countries. It was withdrawn from the French market, together with other triazines, by 30 September $2002 .^{7}$ It can nonetheless remain present in the environment for some years after its last application. Consequently, worldwide potential exposure to atrazine is vast.
As animal data show, atrazine has embryotoxic and embryolethal effects in rodents, but no teratogenic effects have been observed. ${ }^{2}$ In wildlife, male frogs exposed to water polluted with atrazine at levels above $0.1 \mu \mathrm{g} / \mathrm{l}$ show hermaphroditism and retarded gonadal development, due to its endocrine disrupting activity. ${ }^{9}{ }^{10}$ Information about atrazine's reproductive effects in humans is very sparse. Epidemiological studies focused on occupational exposures suggest an increased risk of premature births ${ }^{11}$ and early abortions ${ }^{12}$ associated with preconceptional use of pesticides containing atrazine by the father ${ }^{11}$ and with use during the trimester before conception by the father or mother. ${ }^{12}$ Munger et al conducted the only epidemiological study evaluating the relation between atrazine exposure and reproductive outcomes in the general population. They found higher rates of intrauterine growth retardation (IUGR) in communities with high atrazine levels $(2.1 \mu \mathrm{g} / \mathrm{l})$ in their drinking water than in communities of similar characteristics but lower atrazine levels, after adjustments for potential confounders. ${ }^{13}$ The preliminary results from this ecologic study have not been replicated, and reproductive effects related to atrazine exposure in the general population are far from clear.

We conducted a study based on the birth records in Finistère (France), a highly agricultural administrative

Abbreviations: DEA, desetylatrazine; DIA, deisoprylatrazine; GAC granulated active carbon; IUGR, intrauterine growth retardation; LBW, low birth weight; SGA, small-for-gestational-age; UDI, water distribution unit 
Table 1 Description of atrazine levels in the water distribution units (UDIs) included in the study, by size of population supplied

\begin{tabular}{|c|c|c|c|c|c|c|}
\hline Population supplied & No. UDI & $\begin{array}{l}\text { No. atrazine } \\
\text { measurements }\end{array}$ & No. $<$ DL & No. $>0.1 \mu \mathrm{g} / \mathrm{l}$ & $\begin{array}{l}\text { Geom. mean atrazine } \\
\text { level (excluding }<\mathrm{DL} \text { ) }\end{array}$ & $\begin{array}{l}\text { Geom. mean atrazine } \\
\text { level (including }<\mathrm{DL} \text { ) }\end{array}$ \\
\hline \multicolumn{7}{|l|}{ Raw water } \\
\hline$<4000$ & 85 & 664 & $394(59 \%)$ & $119(18 \%)$ & 0.091 & 0.027 \\
\hline $4000-20000$ & 20 & 495 & $204(41 \%)$ & $118(24 \%)$ & 0.092 & 0.040 \\
\hline$>20000$ & 6 & 589 & 206 (35\%) & $178(30 \%)$ & 0.098 & 0.047 \\
\hline Missing & 1 & & & & & \\
\hline Overall & 112 & 1748 & $804(46 \%)$ & $415(24 \%)$ & 0.094 & 0.036 \\
\hline May to September & & 916 & $347(38 \%)$ & $312(34 \%)$ & 0.122 & 0.052 \\
\hline October to April & & 832 & $457(55 \%)$ & $103(12 \%)$ & 0.063 & 0.025 \\
\hline \multicolumn{7}{|l|}{ Treated water } \\
\hline$<4000$ & 85 & 235 & $140(60 \%)$ & $37(16 \%)$ & 0.079 & 0.024 \\
\hline $4000-20000$ & 20 & 285 & $168(59 \%)$ & $43(15 \%)$ & 0.077 & 0.025 \\
\hline$>20000$ & 6 & 393 & $219(56 \%)$ & $40(10 \%)$ & 0.065 & 0.023 \\
\hline Missing & 1 & & & & & \\
\hline Overall & 112 & 913 & $527(58 \%)$ & $120(13 \%)$ & 0.071 & 0.024 \\
\hline May to September & & 520 & $235(45 \%)$ & $103(20 \%)$ & 0.081 & 0.033 \\
\hline October to April & & 393 & $292(74 \%)$ & $17(4 \%)$ & 0.049 & 0.015 \\
\hline
\end{tabular}

district in France, to evaluate the risks of preterm delivery, low birth weight (LBW), and small-for-gestational-age (SGA) status associated with atrazine levels in municipal drinking water.

\section{METHODS}

\section{Study area}

The district of Finistère occupies a surface of $6785 \mathrm{~km}^{2}$ in the western part of Brittany. Its population (850 000 in 1998) resides in 283 municipalities, which contain from 85 to 150000 inhabitants and have a median size of 3000; $81 \%$ of these municipalities are considered rural. Agricultural activity is predominant and essentially involves livestock, mainly pigs and poultry, together with maize production for the animals and a sector of vegetable production. In 1997, 280 tons of pesticides were used in the maize production area of Finistère. The principal compound was atrazine (71 tons). Pesticide use averaged $1 \mathrm{~kg}$ per hectare per year.

\section{Study population and individual data}

We identified all live births in Finistère from 1 October 1997, to 30 September $1998(\mathrm{n}=9721)$. Data came from the district office of maternal and childhood protection, which obtained it from infant health or "day 8 " certificates completed by the hospital or clinic before the infant's discharge. These certificates are mandatory and are an essential prerequisite for the financial allowances available at birth, and they are handled by the hospitals rather than parents. They are therefore likely to include practically all births. The available information was sex, birth weight, gestational age (weeks of amenorrhea, reported by obstetrical staff at birth), maternal age, number of previous pregnancies, number of visits to the doctor during pregnancy, parents' occupations, and municipality of residence at birth. Although head circumference and body length were also available, we did not consider these variables in the analysis because of their unreliable reporting and the potential for measurement error in newborns. We excluded from the analysis multiple births and newborns with congenital malformations $(n=306)$, because reporting of the types of malformations at birth is often missing and is considered too unreliable to justify their analysis.

\section{Outcomes}

We evaluated three birth outcomes: LBW (birth weight less than $2500 \mathrm{~g}$ ), preterm delivery (gestational age younger than 37 weeks), and SGA status, which was defined as a birth weight below the 10th centile for gestational age, based on population growth curves obtained from 100716 births in different French regions between 1984 and 1988. ${ }^{14}{ }^{15}$

\section{Pesticide measurements}

The district health and social affairs bureau (DDASS, Direction Départementale des Affaires Sanitaires et Sociales) regularly assesses pesticide levels in the drinking water. The number of atrazine measurements by municipality was proportional to population size, as required by statute. Municipalities were split or grouped into water distribution units (UDI), that is, geographic areas receiving water from the same source and the same administrative unit. Water quality was considered homogeneous within UDIs. We excluded 138 of the 283 municipalities in Finistère, because they either had fewer than two measurements of atrazine during the study period, or had more than one UDI from different sources within the municipality, and none supplied at least $80 \%$ of the population. Atrazine levels were assumed to be homogeneous within the municipalities we included (112 UDIs).

We had available to us 2661 atrazine measurements from samples taken from the included UDIs from 1990 to 1998; 1748 were taken from raw water (before treatment) and 913 from treated water (table 1). Date, sampling location, type of water (raw/treated), and UDI name were available for each measurement. Each UDI accounted for 2-285 atrazine measurements (median 26).

The atrazine degradation products desetylatrazine (DEA) and deisoprylatrazine (DIA) were measured in 1430 and 1386 water samples respectively. Other pesticides, including simazine (2769 water samples) and alachlor (901 water samples dating back to 1993) were analysed. Most measurements were below the detection limit (74\% of those for DEA, $99 \%$ for DIA, $86 \%$ for simazine, and $97 \%$ for alachlor), and we did not consider these compounds further in the analysis.

\section{Variability of atrazine levels}

Our first step in creating an exposure index for municipalities was studying the factors of variability for atrazine levels. When the atrazine level was below the detection limit, we attributed to it a value of half the detection limit. We limited analyses of variability to distribution units with more than 30 atrazine measurements. These accounted for 20 UDIs ( $18 \%$ of those included) and $75 \%$ of the total atrazine measurements.

An analysis of variance (ANOVA) to the log transformed atrazine variable including year, month, and UDI showed that the three factors combined explained 33\% of the total 


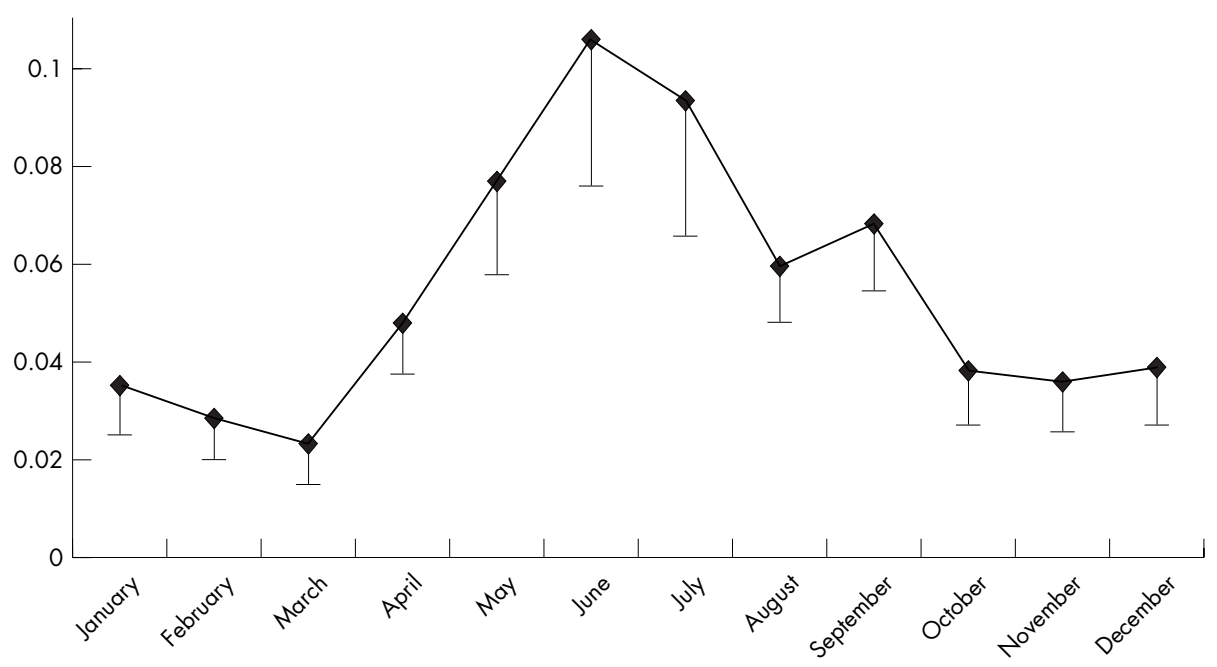

Figure 1 Geometric mean of atrazine levels in raw water by month ( $\mu \mathrm{g} / \mathrm{l}$, in the $y$ axis) and lower $95 \%$ confidence interval, estimated from an analysis of variance adjusted for year and water distribution unit.

variability. Based on the partial mean square, season was the most important source of variability, followed by the geographical and annual variability. The geometric means of the atrazine levels predicted by ANOVA according to month, adjusted for year and UDI, showed that atrazine levels peaked from May to September, in both raw (fig 1) and treated water. Predicted geometric means of atrazine by year, adjusted by seasonal and geographic variation, showed a random variability over the years, in raw and treated water. Atrazine levels in treated water (any treatment) were significantly lower than in raw water. Reduction was more pronounced when filtration with granulated active carbon (GAC) was used (reduction of 63\%), but it was also found in treatment plants that did not apply GAC filtration (48\%).

\section{Atrazine exposure index}

Maternal municipality of residence on the date of birth was used to attribute individual atrazine exposure levels. The precise addresses were not available. We used atrazine levels in municipal drinking water as a marker of exposure to atrazine. All measurements from 1990 through 1998 were used because: (1) we had few measurements for the pregnancy period; and (2) atrazine levels varied randomly for each municipality over the years. We calculated the geometric mean of atrazine levels for each UDI for the MaySeptember period and from 1990 to 1998, separately for measurements in raw and treated water. Variables were created to indicate the number of atrazine measurements and the proportion of measurements for each UDI below the detection limit (separately for raw and treated water). We merged these exposure variables with individual data by municipality of residence (with municipal levels equivalent to those for its principal UDI, as defined above).

\section{Statistical analysis}

Three separate analyses were run, one for each of the three outcomes. We calculated odds ratios (OR) and 95\% confidence intervals (CI) of preterm delivery, LBW, and SGA status, for tertiles of atrazine levels (geometric means), using unconditional logistic regression and adjusting for sex, maternal age, and percentage of samples below the detection limit. Additional adjustment for parity, number of prenatal consultations, and parents' occupations did not affect the results; they also reduced the number of subjects considerably, because of missing values. Probability values for linear trend were calculated.
We examined atrazine levels by size of municipality, grouping the study subjects below and above the median population size (approximately 3000 inhabitants), and found no significant difference according to this variable. To check further for potential confounding or effect modification by population size, the population variable (dichotomous, divided at the median) was introduced in the logistic models. Results were not affected and the p value was not significant. Finally, stratification by population size did not yield significantly different ORs.

On the basis of the gestational age and birth date we calculated conception dates, and variables were created to identify births for which the first (months 1, 2, and 3), second (months 4-6), and third (months 7-9) trimesters of pregnancy developed in whole or in part during the MaySeptember period. For each such trimester (that overlapped in whole or part with May-September), we calculated the ORs and 95\% CIs of LBW, preterm delivery, and SGA status, compared with other pregnancies for which the same trimester occurred totally from October to April. Logistic regression, adjusting for sex, maternal age, and atrazine level during May to September, was used to calculate ORs and 95\% CIs.

We calculated the number of months of each trimester of pregnancy that occurred from May to September. ORs of all three outcomes were calculated, with adjustments for sex, maternal age, and atrazine level from May to September. Probability values for linear trend were calculated. Analyses were conducted with STATA version 8 .

\section{RESULTS}

The study population comprised 3510 births in 145 municipalities. The municipalities included were slightly smaller (average population 2268 inhabitants; range 215-17 607) than those excluded (average 3867; range 84-153 099). Unemployment rates were similar in both groups $(9.7 \%)$. The percentages of LBW infants, premature births, and SGA newborns were also similar in both populations.

The percentage of atrazine measurements below the detection limit from October to April was higher than from May to September. The highest percentage of measurements above $0.1 \mu \mathrm{g} / \mathrm{l}$ occurred in the May-September peak period (table 1).

Of the 3510 births analysed, 137 were premature deliveries, 163 met the definition of LBW, and 241 were SGA. In all, 2915 newborns were normal births (information on the 


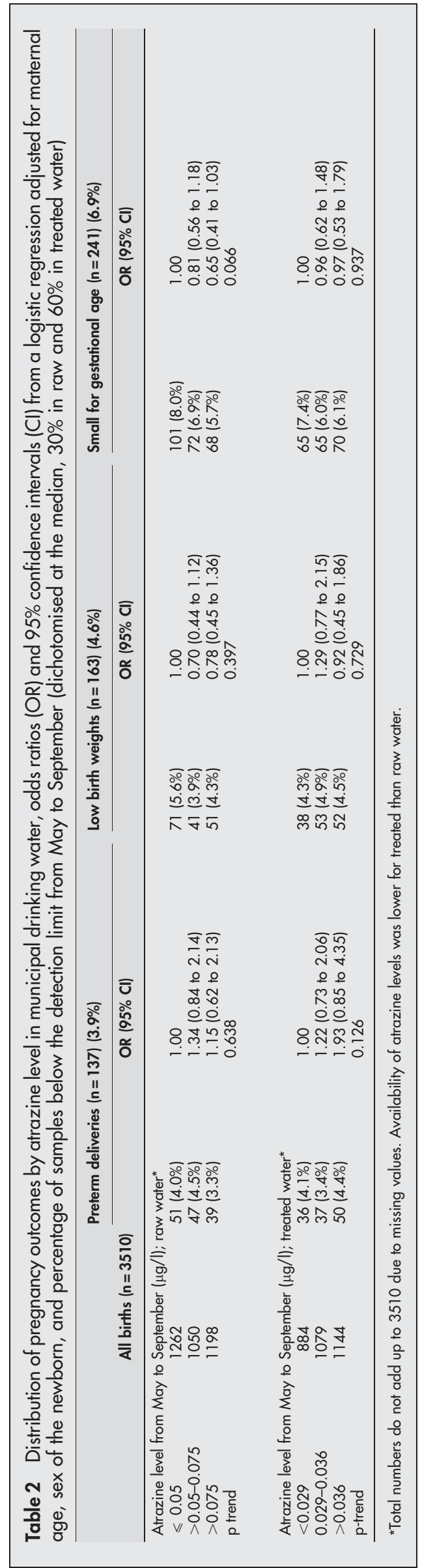

outcomes was missing for the remaining 54 newborns). Fifty two per cent of all newborns were boys, and the sex distribution was the same in the population with adverse outcomes as in the normal population. Maternal age (average 29 years, standard deviation 4.5), number of previous pregnancies, and occupational categories of the mother and the father were also similar for the populations with adverse outcomes and normal births. Information about the number of prenatal consultations was missing for almost half the study population. The data available showed that this number was significantly lower among mothers with premature births.

The distributions of maternal age, sex of the newborn, mother's occupation, and number of previous pregnancies were similar across atrazine exposure levels. The number of prenatal visits differed slightly across atrazine levels, but no clear pattern was visible. The women with no prenatal consultations were mostly in the lowest $(43 \%)$ or highest (36\%) tertile of atrazine exposure. The fathers' occupations, on the other hand, were not evenly distributed across exposure levels. Those working in agriculture were primarily in the highest total exposure tertile (which contained $44 \%$ of all agriculture workers), intermediate professionals were mainly in the lowest tertile (40\%), unemployed and students were mainly in the lowest $(33 \%)$ or intermediate tertile $(40 \%$ of total unemployed and students), and temporary workers were mainly in the lowest tertile (50\%). Executives, upperlevel professionals, and blue-collar workers were equally distributed among the atrazine exposure tertiles.

Table 2 reports the proportion of preterm, LBW, and SGA infants according to municipal atrazine level. This level was not clearly associated with an increased risk of either LBW or SGA status (table 2). The risk of preterm delivery increased slightly, but confidence intervals were wide and included 1 (table 2).

We found a slightly increased risk of SGA status if the third trimester occurred partly or completely during the MaySeptember period, compared with third trimesters from October to April, and an increased risk of prematurity of borderline significance if the first trimester occurred from May to September (table 3).

A duration-response pattern was found for SGA risk and the number of months of the third trimester occurring in May to September, compared with pregnancies whose third trimester occurred entirely from October to April (table 4). The risks of preterm delivery and LBW did not increase with duration of the third trimester that fell within the period from May to September, and no dose-response trend was observed. The risk of preterm delivery did not show a doseresponse pattern according to the number of months of the first trimester that overlapped with the May-September period.

\section{DISCUSSION}

We found that atrazine levels in municipal drinking water throughout pregnancy were not associated with an increased risk of LBW or SGA birth, at the levels to which the study population was exposed. Results suggest an association with prematurity. We identified an increased risk of SGA birth when the third trimester occurred in whole or in part during May to September (the period of peak atrazine levels in water). We also found a duration-response for the number of months of the third trimester that coincided with this period.

We identified all births during one year in a district in France, and we analysed a sub-sample of them. The percentages of LBW, premature, and SGA births were similar among the included and excluded populations. LBW (4.7\%) and premature birth $(4.2 \%)$ rates in the study population were slightly lower than the 1998 nationwide rates in France 
Table 3 Adjusted OR* for the outcomes studied, by trimesters of pregnancy that overlapped with any part of May-September compared with October-April

\begin{tabular}{|c|c|c|c|c|c|c|}
\hline & \multicolumn{2}{|l|}{ Preterm delivery } & \multicolumn{2}{|l|}{ Low birth weight } & \multicolumn{2}{|c|}{ Small-for-gestational-age } \\
\hline & OR $(95 \% \mathrm{Cl})$ & $n$ & OR $(95 \% \mathrm{Cl})$ & $n$ & OR $(95 \% \mathrm{Cl})$ & $n$ \\
\hline \multicolumn{7}{|l|}{ First trimester } \\
\hline October-April & 1.00 & 47 & 1.00 & 66 & 1.00 & 118 \\
\hline May-September & 1.36 (0.95 to 1.95$)$ & 89 & 0.95 (0.68 to 1.32 ) & 87 & $0.73(0.56$ to 0.96$)$ & 121 \\
\hline \multicolumn{7}{|l|}{ Second trimester } \\
\hline October-April & 1.00 & 57 & 1.00 & 72 & 1.00 & 117 \\
\hline May-September & 1.09 (0.77 to 1.54$)$ & 79 & $0.88(0.63$ to 1.21$)$ & 81 & $0.82(0.63$ to 1.06$)$ & 120 \\
\hline \multicolumn{7}{|l|}{ Third trimester } \\
\hline October-April & 1.00 & 61 & 1.00 & 55 & 1.00 & 83 \\
\hline May-September & 0.83 (0.58 to 1.18$)$ & 69 & $1.24(0.88$ to 1.74$)$ & 93 & $1.37(1.04$ to 1.81$)$ & 155 \\
\hline
\end{tabular}

$\mathrm{OR}$, odds ratio; $\mathrm{Cl}$, confidence interval; $\mathrm{n}$, number of outcomes.

*Obtained from logistic regression adjusting for sex of the newborn, maternal age, and geometric mean atrazine level in May-September.

(5.0\% and $4.7 \%$ respectively). ${ }^{16}$ Accordingly, there was no evidence of selection bias. Recall bias was not a concern here since exposure status was not ascertained through information provided by the mother.

We had no data about potential confounders, such as maternal smoking or alcohol consumption, and thus could not evaluate them. There are, however, no reasons to think that these variables might be related to exposure and could thus confound the results. Although conclusive evidence is not available, some environmental exposures, including disinfection by-products, ${ }^{17-19}$ air pollution, ${ }^{20-22}$ polychlorinated biphenyls, ${ }^{23}$ and lead $^{24}$ have been related to the pregnancy outcomes we evaluate here. Confounding by some of these exposures might be a concern, especially for those that show a seasonal pattern that could coincide with the peak period we identified. However, we did not have data to evaluate this.

The main limitation of this study, which may partially explain the lack of associations with atrazine levels, arises from the exposure assessment. The individual information available on birth certificates about exposure related habits was limited. We had neither complete addresses nor information on the source and amount of drinking water consumed. We used atrazine levels in municipal drinking water as a surrogate for individual exposure, which can occur from exposure through ingestion, inhalation, and dermal routes. Subjects were classified according to the geometric mean of the atrazine level in their municipal water supply during the period that best discriminated exposures, since we did not have enough atrazine data to know actual levels during the pregnancy. Moreover, exposure to atrazine could have occurred through other situations not considered here: manipulation and application by farmers, atmospheric deposition, ${ }^{25}$ consumption of contaminated foods, etc. Consequently, some exposure misclassification may have

Table 4 Adjusted $\mathrm{OR}^{*}$ of small-for-gestational-age status, by the number of months of the third trimester that overlapped with the May-September period

\begin{tabular}{lll}
\hline & OR $(95 \% \mathrm{Cl})$ & $\mathbf{n}$ \\
\hline No. months of the 3rd trimester in May-September & \\
0 month & 1.00 & 83 \\
1 month & $1.25(0.84$ to 1.86$)$ & 39 \\
2 months & $1.36(0.96$ to 1.93$)$ & 57 \\
3 months & $1.48(1.04$ to 2.09$)$ & 59 \\
p trend & 0.019 & \\
\hline
\end{tabular}

OR, odds ratio; $95 \% \mathrm{Cl}, 95 \% \mathrm{Cl} ; \mathrm{n}$, number of small for gestational age newborns.

*Obtained from logistic regression adjusting for sex of the newborn, maternal age, and geometric mean atrazine level in May-September. been produced, probably attenuating the magnitude of the association.

Atrazine levels in our study municipalities were low, compared with the literature. The geometric mean in raw water for the May-September period was $0.052 \mu \mathrm{g} / \mathrm{l}$. The study of Munger et al reported a median atrazine level of $2.1 \mu \mathrm{g} / \mathrm{l}$ in the Iowa counties with high exposure and an average level of $0.6 \mu \mathrm{g} / \mathrm{l}$ in all other Iowa surface waters. ${ }^{13}$ The low levels of exposure may partly explain the lack of associations. In addition, the exposure range was narrow, and dose-response could not be precisely evaluated.

Multiple exposures may be another concern in our study, since subjects are probably not exposed only to atrazine. We had a list of the pesticides measured in Finistère from 1990 to 1998, the number of total measurements and of measurements above the detection limit (DL). In addition to atrazine, 64 pesticides were analysed in water, and levels were low: 41 compounds were below the DL in all analyses, 20 in more than $90 \%$ of measurements, and three in $70 \%$ of measurements. Atrazine was therefore the predominant pesticide in municipal water throughout the study areas. Many of these pesticides are more lipophilic and less soluble in water than atrazine, and exposure to them may occur through routes other than ingestion of drinking water.

We found an association between SGA status for "ever" exposure during the third trimester to the peak atrazine period as well as a duration-response pattern. This period coincides with atrazine application and the months immediately afterwards. We could speculate about more intense pesticide exposure during these months, resulting from intensive agricultural activity. Our data are too limited to conclude that the seasonal association is necessarily explained by atrazine. Other factors or combinations of factors that may follow a similar seasonal pattern (including other water pollutants, meteorological conditions, etc) may explain our results.

Studies that have examined the association between environmental exposures during specific time windows of pregnancy and increased risk of adverse birth outcomes show heterogeneous results. ${ }^{20-22} 2728$ Some studies report that exposure to air pollutants during the early stages of pregnancy are associated with an increased risk of IUGR ${ }^{29} 30$ and provide hypotheses of biological mechanisms to explain the association. The evidence is far from conclusive, however, and different risk factors may act through different mechanisms.

We evaluated only some of the outcomes that may be related to atrazine exposure. Specifically, we were not able to evaluate other major pregnancy outcomes that might be also associated with atrazine, such as early abortion, since information provided by birth certificates is limited, and these certificates are filed only for pregnancies that reached 
28 weeks of gestation. Atrazine exposure has been associated with other adverse health effects, such as reduced sperm quality $^{31}$ and cancer..$^{32}{ }^{33}$ Since evidence of genotoxic activity is weak, ${ }^{2}$ mechanisms of action hypothesised for atrazine may involve an endocrine disrupting pathway ${ }^{10}$ or immune system alterations. ${ }^{34}$

Our results confirm that evaluating different time windows of exposure during pregnancy provides additional insight to that obtained looking at the entire pregnancy; they suggest that the third trimester of pregnancy is the vulnerable period for an increased risk of being born SGA. Since atrazine levels in the water were low, the exposure range was narrow, and no dose-response was found, we cannot conclude that atrazine levels in drinking water explain the seasonal pattern we observed. Other factors following a seasonal pattern similar to atrazine levels cannot be ruled out and more research is needed to identify them.

\section{ACKNOWLEDGEMENTS}

We are grateful to Manolis Kogevinas for his comments about the manuscript. CM Villanueva was funded by the INSERM/DURSI agreement on individual exchange of researchers. We are grateful to Jo Ann Cahn for her careful revision of the manuscript.

\section{Authors' affiliations}

C M Villanueva, Respiratory and Environmental Health Research Unit, Institut Municipal d'Investigació Mèdica (IMIM), C/Doctor Aiguader, 80, 08003-Barcelona, Spain

C Chevrier, S Cordier, Institut National de la Santé et la Recherche Médicale (INSERM) U 625, Université de Rennes 1, Campus Beaulieu, Av. Général Leclerc, 35042-Rennes Cedex, France

G Durand, Pôle Analytique des Eaux, 120, rue A. de Rochon, BP 5229280 Plouzané, France

M-B Coutté, Santé Publique, Hygiène Hospitalière et Evaluation, Centre Hospitalier Universitaire (CHU) de Brest, Hôpital Morvan, 5 Avenue Foch, 29200-Brest, France

Competing interests: none

\section{REFERENCES}

1 Ikonen R, Kangas J, Savolainen H. Urinary atrazine metabolites as indicators for rat and human exposure to atrazine. Toxicol Lett 1988;44:109-12.

2 International Agency for Research on Cancer (IARC). Some chemicals that cause tumors of the kidney or urinary bladder in rodents and some other substances, IARC monographs on the evaluation of carcinogenic risks to humans, Vol. 73. Lyon: IARC Scientific Publications, 1999.

3 Quaghebeur D, Smet BD, Wulf ED, et al. Pesticides in rainwater in Flanders, Belgium: results from the monitoring program 1997-2001. J Environ Monit 2004;6: 182-90.

4 Kuang Z, McConnell LL, Torrents A, et al. Atmospheric deposition of pesticides to an agricultural watershed of the Chesapeake Bay. J Environ Qual 2003;32:1611-22.

5 Steinheimer TR, Scoggin KD. Fate and movement of atrazine, cyanazine, metolachlor and selected degradation products in water resources of the deep Loess Hills of Southwestern lowa, USA. J Environ Monit 2001 ;3:126-32.

6 Council Directive 98/83/EC on the quality of water intended for human consumption, adopted on 3 November 1998, L 330/32 Official Journal of the European Communities 5.12.98.

7 Frost G. http://www.mindfully.org/Pesticide/Atrazine-Banned-France.htm, Reuters News Service. 2004

8 International Agency for Research on Cancer (IARC). Occupational exposures in insecticide application, and some pesticides, IARC monographs on the evaluation of carcinogenic risks to humans, Vol. 53. Lyon: IARC Scientific Publications, 1991.
9 Hayes T, Haston K, Tsui $M$, et al. Herbicides: feminization of male frogs in the wild. Nature 2002;419:895-6.

10 Hayes T, Haston K, Tsui M, et al. Atrazine-induced hermaphroditism at $0.1 \mathrm{ppb}$ in American leopard frogs (Rana pipiens): laboratory and field evidence. Environ Health Perspect 2003;111:568-75.

11 Savitz DA, Arbuckle T, Kaczor D, et al. Male pesticide exposure and pregnancy outcome. Am J Epidemiol 1997;146:1025-36.

12 Arbuckle TE, Zhiqiu L, Mery LS. An exploratory analysis of the effect of pesticide exposure on the risk of spontaneous abortion in an Ontario farm population. Environ Health Perspect 2001;109:851-7.

13 Munger R, Isacson $\mathrm{P}, \mathrm{Hu} \mathrm{S}$, et al. Intrauterine growth retardation in lowa communities with herbicide-contaminated drinking water supplies. Environ Health Perspect 1997:105:308-14.

14 Mamelle N, Munoz F, Grandjean Hplgdt A. Croissance foetal à partir de I'étude AUDIPOG. I. Etablissement de courbes de référence. J Gynecol Obstet Biol Reprod 1996;25:61-70.

15 Mamelle N, Munoz F, Martin JL, et al. Croissance foetal à partir de l'étude AUDIPOG. II. Application au diagnostic de retard de croissance intra-utérin. J Gynecol Obstet Biol Reprod 1996;25:71-7.

16 Blondel B, Norton J, Mazaubrun C, et al. Enquete Nationale Périnatale. Ministère de l'Emploi et de la Solidarité and Institut National de la Santé et de la Recherche Médicale. 1998.

17 Graves CG, Matanoski GM, Tardiff RG. Weight of evidence for an association between adverse reproductive and developmental effects and exposure to disinfection by-products: a critical review. Regul Toxicol Pharmacol 2001;34:103-24.

18 Bove F, Shim Y, Zeitz P. Drinking water contaminants and adverse pregnancy outcomes: a review. Environ Health Perspect 2002;110(suppl 1):61-74.

19 Nieuwenhuijsen MJ, Toledano MB, Eaton N, et al. Chlorination disinfection byproducts in water and their association with adverse reproductive outcomes: a review. Occup Environ Med 2000;57:73-85.

20 Ritz B, Yu F, Chapa G, et al. Effect of air pollution on preterm birth among children born in Southern California between 1989 and 1993. Epidemiology 2000:11:502-11.

21 Wilhelm M, Ritz B. Residential proximity to traffic and adverse birth outcomes in Los Angeles county, California, 1994-1996. Environ Health Perspect 2003;111:207-16.

22 Bobak M. Outdoor air pollution, low birth weight, and prematurity. Environ Health Perspect 2000;108:173-6.

23 Baibergenova A, Kudyakov R, Zdeb M, et al. Low birth weight and residential proximity to PCB-contaminated waste sites. Environ Health Perspect 2003;111:1352-7.

24 McMichael AJ, Vimpani GV, Robertson EF, et al. The Port Pirie cohort study: maternal blood lead and pregnancy outcome. J Epidemiol Community Health 2004;40: 18-25.

25 Blanchoud H, Garban B, Ollivon D, et al. Herbicides and nitrogen in precipitation: progression from west to east and contribution to the Marne river (France). Chemosphere 2002;47:1025-31.

26 Catenacci G, Maroni M, Cottica D, et al. Assessment of human exposure to atrazine through the determination of free atrazine in urine. Bull Environ Contam Toxicol 1990;44:1-7.

27 Yang CY, Tseng YT, Chang CC. Effects of air pollution on birth weight among children born between 1995 and 1997 in Kaohsiung, Taiwan. J Toxicol Environ Health A 2003;66:807-16.

28 Lee BE, Ha EH, Park HS, et al. Exposure to air pollution during different gestational phases contributes to risks of low birth weight. Hum Reprod 2003; 18:638-43

29 Dejmek J, Selevan SG, Benes I, et al. Fetal growth and maternal exposure to particulate matter during pregnancy. Environ Health Perspect 1999; 107:475-80

30 Dejmek J, Solansky I, Benes I, et al. The impact of polycyclic aromatic hydrocarbons and fine particles on pregnancy outcome. Environ Health Perspect 2000;108:1159-64.

31 Swan SH, Kruse RL, Liu F, et al. Semen quality in relation to biomarkers of pesticide exposure. Environ Health Perspect 2003;111:1478-84.

32 Birnbaum LS, Fenton SE. Cancer and developmental exposure to endocrine disruptors. Environ Health Perspect 2003;111:389-94.

33 Van Leeuwen JA, Waltner-Toews D, Abernathy T, et al. Associations between stomach cancer incidence and drinking water contamination with atrazine and nitrate in Ontario (Canada) agroecosystems, 1987-1991. Int J Cancer 1999;28:836-40

34 Christin MS, Menard L, Gendron AD, et al. Effects of agricultural pesticides on the immune system of Xenopus laevis and Rana pipiens. Aquat Toxicol 2004;67:33-43. 